\title{
Impact of High Pressure Homogenization (HPH) Treatment on the Nutritional Quality of Egg/Yogurt, Vegetable and Fruit Based Creams
}

\author{
Mattia Di Nunzio $^{1 *}$, Lucia Vannini ${ }^{1,2}$, Nadia Tossani ${ }^{3}$, Francesca Patrignani $^{2}$, \\ Rosalba Lanciotti ${ }^{1,2}$, Alessandra Bordoni ${ }^{1,2}$ \\ ${ }^{1}$ Interdepartmental Centre for Industrial Agri-Food Research, Alma Mater Studiorum-University of Bologna, Cesena, Italy; \\ ${ }^{2}$ Department of Agri-Food Sciences \& Technologies, Alma Mater Studiorum-University of Bologna, Cesena, Italy; ${ }^{3}$ Dipartimento di \\ Scienze Biomediche e Neuromotorie, Alma Mater Studiorum-University of Bologna, Bologna, Italy. \\ Email: ${ }^{*}$ mattia.dinunzio@unibo.it
}

Received November $6^{\text {th }}, 2013$; revised December $6^{\text {th }}, 2013$; accepted December $13^{\text {th }}, 2013$

Copyright (C) 2014 Mattia Di Nunzio et al. This is an open access article distributed under the Creative Commons Attribution License, which permits unrestricted use, distribution, and reproduction in any medium, provided the original work is properly cited. In accordance of the Creative Commons Attribution License all Copyrights (C) 2014 are reserved for SCIRP and the owner of the intellectual property Mattia Di Nunzio et al. All Copyright (C) 2014 are guarded by law and by SCIRP as a guardian.

\section{ABSTRACT}

The food industry has made large investments in processing facilities relying mostly on conventional thermal processing technologies with well-established reliability and efficacy. These techniques have important disadvantages such as off flavors, destruction of nutrients, and other losses of product quality. Non thermal processing is a key factor for preserving or improving the nutritional value of food, and high pressure homogenization (HPH) processing is now a celebrated option experiencing worldwide commercial growth. Notwithstanding, little is known on the impact of HPH treatments on the nutritional value of food. In this study we have evaluated the possible modification induced by HPH treatment in egg-yogurt, mixed vegetable, and mixed fruit creams. Our results evidence that HPH does not affect the nutritional quality of lipids and does not cause lipolysis, lipid peroxidation and vitamin E loss. In plant food products, HPH preserved or improved the nutritional quality, suggesting its use as valid alternative to thermal pasteurization for obtaining high quality products with preserved nutritional characteristics. Although further investigations are needed, especially at extreme pressure and temperature combinations, our results open new perspectives for the production of ambient stable products with good nutritional value, and contribute to process optimization.

\section{KEYWORDS}

High Pressure Homogenization; Nutritional Quality

\section{Introduction}

It is well known that thermal processing generally applied for extending shelf life of food products can affect food nutritional value due to nutrient and bioactive sensitivity to heat. In addition, thermal processing can cause the parallel formation of dangerous oxidized by-products. Lipid oxidation is one of the major degradative processes in food; it results in significant generation of cytotoxic compounds and free radicals which can oxidize vitamins, thus impairing the nutritional quality [1]. Degradation of

${ }^{*}$ Corresponding author. lipids is accelerated by high temperature and high energy radiation.

Food composition tables are representative of foodstuffs consumed in their raw state, and they do not consider that concentration, availability, and biological activity of nutrients may be changed by processing. Due to the relative instability of many compounds, thermal processing can profoundly affect the nutritional value of vegetables [2] which contain many nutritional and healthful constituents, including minerals, vitamins, dietary fibers, and phytochemicals, and are considered to be the major contributors of antioxidant dietary intake [3]. 
As an example ascorbic chemical oxidation and/or thermal degradation is a consequence of pasteurization and sterilization [4].

In this light the development of mild non thermal processing is a key factor for preserving or improving the nutritional value of food. In this perspective, high pressure homogenization (HPH), which ensures product stability, shelf life, and taste [5] is considered one of the most promising non thermal food-processing technologies. Multipass homogenization treatment increases the safety features of food; Patrignani et al. [6] evidenced that the multi-pass high pressure treatment at $100 \mathrm{MPa}$ of liquid whole egg inoculated with 7 and $4 \log$ CFU $/ \mathrm{ml} S$. enterica serovar enteritidis results in a first order inactivation kinetic. Furthermore, the HPH ability to potentiate the antimicrobial activity of naturally occurring egg antimicrobials is reported $[7,8]$.

Hyperbaric treatment can also have a positive impact on the technological characteristics of food; as an example, it increases the foaming capacity of liquid whole egg, while having a minor impact on product viscosity. This allows a more flexible utilization of whole liquid eggs in several based-egg products [6].

Although nowadays HPH treatment is a celebrated processing option experiencing worldwide commercial growth, little is known on its impact on the nutritional value of food. In this study we have evaluated the HPH induced nutritional modifications occurring in: 1) an egg-yogurt cream (EYC) formulated with different $\mathrm{NaCl}$ concentrations; 2) a mixed vegetable cream (MVC); and 3) a mixed fruit cream (MFC). EYC nutritional quality was evaluated measuring lipid peroxidation, triglyceride hydrolysis, fatty acid composition, and vitamin $\mathrm{E}$ content. MVC and MFC nutritional quality was assessed by measuring total antioxidant activity (TAA), and vitamin $\mathrm{C}$ content.

\section{Materials and Method}

\subsection{Materials}

Chloroform, methanol, isooctane, isopropanol, diethyl ether, ethanol and n-hexane were purchased from Carlo Erba (Milan, Italy); 2,2'-azino-bis-(3-ethylbenzothiazoline6-sulfonic acid) (ABTS), iodine, potassium iodide, phenolphthalein and anhydrous sodium sulfate were obtained from Sigma (Milan, Italy). All other chemicals and solvents were of the highest analytical grade.

\subsection{Egg-Yogurt Cream (EYC) Formulation}

The formulation used for the preparation of EYC was $60 \%$ $(\mathrm{w} / \mathrm{w})$ sunflower oil, 17\% (w/w) water, $13 \%(\mathrm{w} / \mathrm{w})$ yogurt, $10 \%(\mathrm{w} / \mathrm{w})$ egg, and $\mathrm{NaCl}$ at different concentra- tions $(0 \%, 1 \%$ and $2 \%)$. Briefly, whole egg and salt were mixed at $700 \mathrm{rpm}$ attended by sunflower oil. Yogurt and water were added and mixed with other components at $50 \mathrm{rpm}$. Last, citric acid was included to adjust $\mathrm{pH}$ to 5.

\subsection{Mixed Vegetable (MVC) and Fruit (MFC) Creams Formulation}

The mixed vegetable cream had the following composition: $28.6 \%(\mathrm{w} / \mathrm{w})$ zucchini, $28.6 \%(\mathrm{w} / \mathrm{w})$ potatoes, $28.6 \%$ $(\mathrm{w} / \mathrm{w})$ beans and $14.2 \%(\mathrm{w} / \mathrm{w})$ water. The mixed fruit cream was made of $32.2 \%(\mathrm{w} / \mathrm{w})$ fresh orange pulp, $32.2 \%$ $(\mathrm{w} / \mathrm{w})$ fresh carrots, $32.2 \%(\mathrm{w} / \mathrm{w})$ apricot juice and 3.4\% $(\mathrm{w} / \mathrm{w})$ water.

After mixing the ingredients (vegetable or fruits) at $250 \mathrm{rpm}$ under vacuum for $60 \mathrm{sec}$, a blenching $\left(82^{\circ} \mathrm{C}\right.$ for $180 \mathrm{sec}$ ) was performed to inactivate endogenous enzymes. Finally water was added and the mixture cooled down to $2^{\circ} \mathrm{C}$ under agitation at $2800 \mathrm{rpm}$.

\subsection{HPH Treatment}

A continuous industrial-scale high pressure homogenizer (Niro Soavi, Parma, Italy) was used for all the homogenizing treatments (maximum pressure $=400 \mathrm{MPa}$ ). The machine was supplied with $R$ valve. In order to avoid the temperature increase, the products were cooled down to $4^{\circ} \mathrm{C}$ by using a thermal exchanger (Niro Soavi, Parma, Italy). The EYC, MVC and MFC samples were subjected to HPH treatments at different pressure levels up to 400 MPa. In particular the pressure values applied for both MVC and MFC were 0.1, 100, 200, 300 and $400 \mathrm{MPa}$. For the EYC the following pressures were used: 0.1, 70, 100 and $150 \mathrm{MPa}$. The time of treatment was constant and istantaneus $(1.6 \mathrm{~ms})$ regardless the pressure levels and the food matrices.

\subsection{Lipid Extraction and Fatty Acid Composition Analysis}

Total lipids were extracted from EYC according to Di Nunzio et al. [9], and methyl esterified according to Di Nunzio et al. [10]. Fatty acid composition (as methyl esters) was determined by gas chromatography (GC 8000, Fisons, Milano, Italy) using a capillary column (SP 2340, $0.2 \mu \mathrm{m}$ film thickness) at programmed temperature $\left(160^{\circ} \mathrm{C}-210^{\circ} \mathrm{C}\right.$, with a gradient of $\left.8{ }^{\circ} \mathrm{C} / \mathrm{min}\right)$ as previously reported [11]. The gas chromatographic peaks were identified on the basis of their retention time ratio relative to methyl stearate and predetermined on authentic samples. Gas chromatographic traces and peak area evaluations were obtained using a Chrom Card Softwer (Thermo Electron Scientific, Milan, Italy) computing integrator. 


\subsection{Triacylglycerol Hydrolysis.}

Determination of free acidity, considered an indicator of triacylglycerol hydrolysis, was performed by titration using $\mathrm{NaOH}$ as the titrant for the free acids [12]. Free acids contained in $1 \mathrm{~g}$ of sample were dissolved in a neutralized diethyl ether/ethanol $(2: 1, \mathrm{v} / \mathrm{v})$ solution, and titrated while stirring with $0.01 \mathrm{~N} \mathrm{NaOH}$ using $1 \%(\mathrm{w} / \mathrm{w})$ phenolphthalein solution for the detection of the endpoint. Titration was carried out till the formation of persistent $(>10 \mathrm{~s})$ slight violet colour. Free acidity was expressed as percentage of linoleic acid content, since linoleic acid was the most abundant fatty acid in the sample.

\subsection{Conjugated Diene level}

Oxidative damage was assayed in EYC by quantifying the content of conjugated dienes. Conjugated dienes were extracted from $0.1 \mathrm{~g}$ sample according to Chouinard et al. [13] using $3.6 \mathrm{~mL}$ of $\mathrm{n}$-hexane/isopropanol $(3: 2, \mathrm{v} / \mathrm{v})$ solution, followed by through mix and the addition of 2.4 $\mathrm{mL}$ of $7 \%$ sodium sulfate anhydrous solution (w/v). After phase separation, the upper layer was collected and transferred to a test tube, dried under nitrogen infusion, and the lipid residue was redissolved in $25 \mathrm{~mL}$ isooctane. Absorbance was measured at $232 \mathrm{~nm}$ against blank, and conjugated diene concentration expressed as specific extinctions $(\mathrm{K} \lambda)$ calculated by the following formula (1):

$$
k \lambda=1 / g \times A_{b s} \times V / 100
$$

where $g$ is gram of sample weighted and $V$ the dilution.

\subsection{Vitamin E content}

Ten grams of EYC underwent cold saponification using $5 \mathrm{ml} \mathrm{KOH} 50 \%, 100 \mathrm{~mL}$ ethanol, and $200 \mathrm{mg}$ of antioxidant mixture (butylated hydroxytoluene, EDTA, vitamin C). Samples were shaken for $15 \mathrm{~min}$, incubated in the dark overnight, extracted twice with n-hexane, filtered, evaporated under vacuum, and resuspended in 10 $\mathrm{mL}$ of $\mathrm{n}$-hexane. Vitamin $\mathrm{E}$ content was determined by direct phase normal-phase high performance liquid chromatography (NP-HPLC) using a Helwett Pakard-serie1100 Agilent apparatus equipped with a $5-\mu \mathrm{m}$ Luna Si-60-Phenomenex column $(250 \times 4.6 \mathrm{~mm}$ i.d. $)$. The mobile phase was n-hexane/isopropanol (99.2/0.8), in isocratic at a flow rate of $1.5 \mathrm{~mL} / \mathrm{min}$. The UV detector was set at $290 \mathrm{~nm}$. Vitamin E content was calculated by comparison of the respective peak areas to standards, and expressed as $\mathrm{mg} / 100 \mathrm{~g}$ sample. Chromatograms were recorded and processed using HP Chemstation software.

\subsection{Total Antioxidant Capacity (TAC)}

MVC and MFC were homogenized in a food processor, and $10 \mathrm{~g}$ of the homogenized material were dissolved in $30 \mathrm{ml}$ of cold $5 \mathrm{mM}$ phosphate buffered saline, $\mathrm{pH}$ 7.4. Samples were filtered, and the resulting filtrate was used to determine the TAC. All phases of homogenization were done in ice, and each filtrate immediately analysed.

TAC was measured as previously reported [14], on the basis of the ability of the antioxidant molecules in the sample to reduce the radical cation of ABTS, determined by the decolorization of $\mathrm{ABTS}^{+\bullet}$, and measured as the quenching of the absorbance at $734 \mathrm{~nm}$. Values obtained for each sample were compared to the concentrationresponse curve of the standard trolox solution and expressed as micromoles of trolox equivalent (TE) $/ 100 \mathrm{~g}$ sample.

\subsection{Vitamin C Concentration}

Vitamin C content in MVC and MFC was assessed according to Ciancaglini et al. [15]. Samples were homogenized in a food processor without addition of any solvent, and $10 \mathrm{~g}$ of the homogenized material was dissolved in $30 \mathrm{ml}$ of cold water, getting a dilution 1:3 w/v. Samples were then filtered and the resulting filtrate was titrated while stirring with $0.005 \mathrm{M} \mathrm{I}_{2}$ using starch indicator for the detection of the end point. Titration was carried out till the formation of persistent $(>10 \mathrm{~s})$ blueblack starch-iodine complex, and vitamin $\mathrm{C}$ concentration was expressed as $\mathrm{mol} / 100 \mathrm{~g}$ sample.

\subsection{Statistical Analysis}

Data are reported as mean $\pm \mathrm{SD}$. Differences were tested for statistical significance by the one way ANOVA using Tukey's as post test. $\mathrm{P}$ values less than 0.05 were considered statistically significant.

\section{Results}

The EYC fatty acid composition is reported in Figure 1(a). The most concentrated fatty acids were linoleic $>$ oleic > palmitic > stearic acid; myristic, palmitoleic, $\alpha$-linolenic and docosanoic acid were also detected in traces. Neither $\mathrm{NaCl}$ concentration (data not shown) nor the pressure used for treatment caused significant modifications in the fatty acid composition. A representative chromatogram is shown in Figure 1(b).

Free acidity was influenced by $\mathrm{NaCl}$ concentration, while no differences related to HPH treatment were detected comparing samples with the same $\mathrm{NaCl}$ content (Figure 2).

As well, HPH did not cause any increase in lipid peroxidation, measured as concentration of conjugated diene containing lipids, independent of $\mathrm{NaCl}$ concentration (Figure 3).

In samples treated at atmospheric pressure $(0.1 \mathrm{MPa})$ 


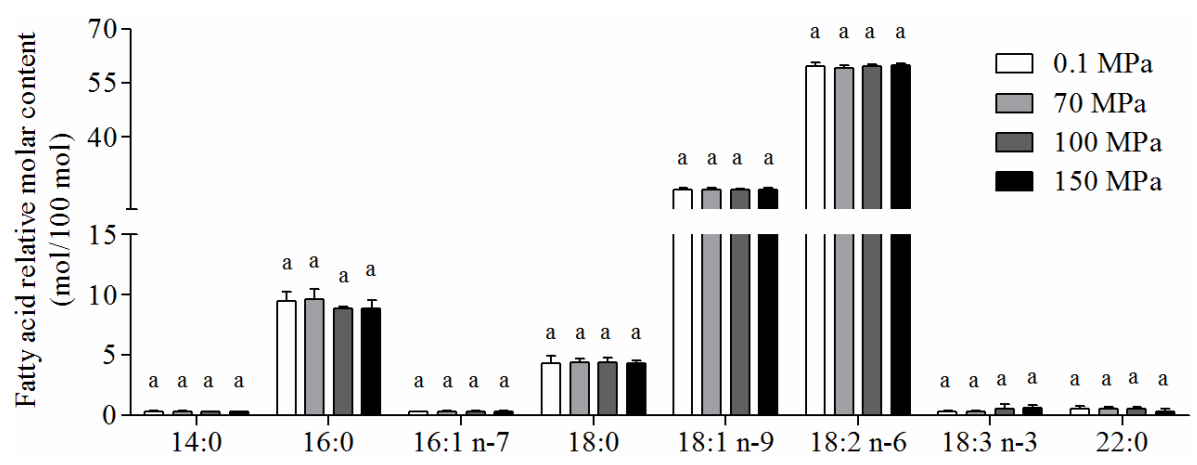

(a)

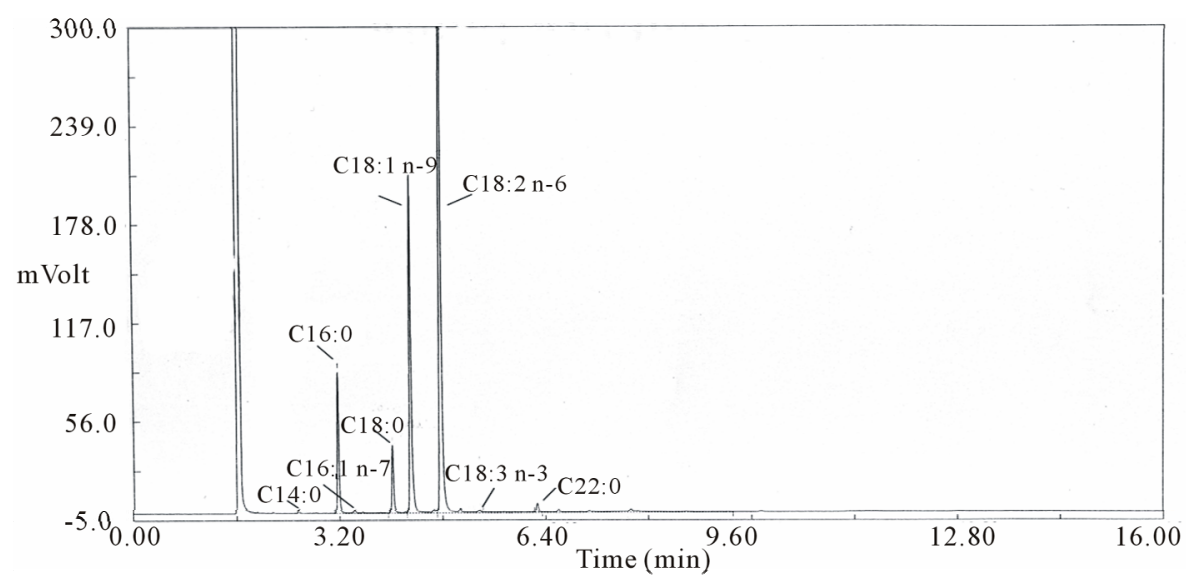

(b)

Figure 1. Fatty acid composition of egg-yogurt cream after different HPH treatments (a) and representative chromatogram (b). Data are means +/- SD. Statistical analysis was by the one way ANOVA (n.s.), using Tukey's as post test: no significant differences were detected among samples treated with HPH at different pressure.

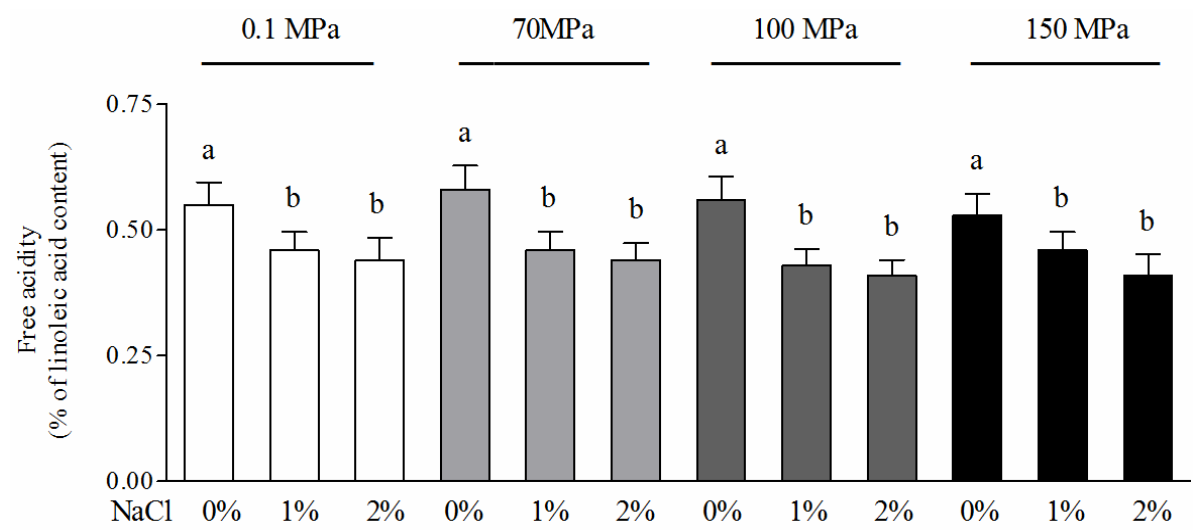

Figure 2. Free acidity of egg-yogurt cream with different $\mathrm{NaCl}$ concentration after different HPH treatments. Data are means $+/-$ SD. Statistical analysis was by the one way ANOVA $(\mathbf{p}<\mathbf{0 . 0 1})$, using Tukey's as post test. Different letters indicate statistical significance (at least $\mathbf{p}<\mathbf{0 . 0 5}$ ).

and at $70 \mathrm{MPa} \mathrm{HPH}$, vitamin $\mathrm{E}$ content appeared dependent on $\mathrm{NaCl}$ concentration, being about $40 \%$ lower in samples containing $1 \%$ or $2 \% \mathrm{NaCl}$ (Figure 4 ). No detrimental effect due to $\mathrm{NaCl}$ concentration was evident in samples treated with the two highest HPH. The highest vitamin $\mathrm{E}$ content was observed in the $1 \% \mathrm{NaCl}$ sample treated at $150 \mathrm{MPa}$.

In the MVC, $300 \mathrm{MPa} \mathrm{HPH}$ treatment significantly increased the TAC (Figure 5(a)), while vitamin $\mathrm{C}$ content was similar in all tested conditions (Figure 5(b)).

In the MFC, $\mathrm{HPH}$ processing did not modify the TAC (Figure 6(a)), while vitamin $C$ increased using the 200 


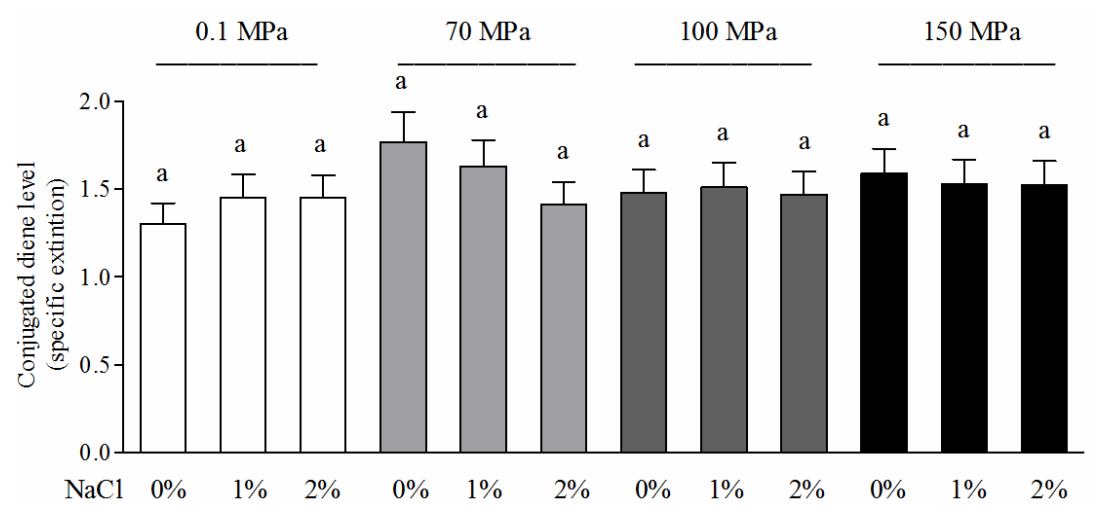

Figure 3. Concentration of conjugated diene containing lipids in egg-yogurt cream with different NaCl concentration after different HPH treatment. Data are means +/- SD. Statistical analysis was by the one way ANOVA (n.s.), using Tukey's as post test: no significant differences were detected among samples.

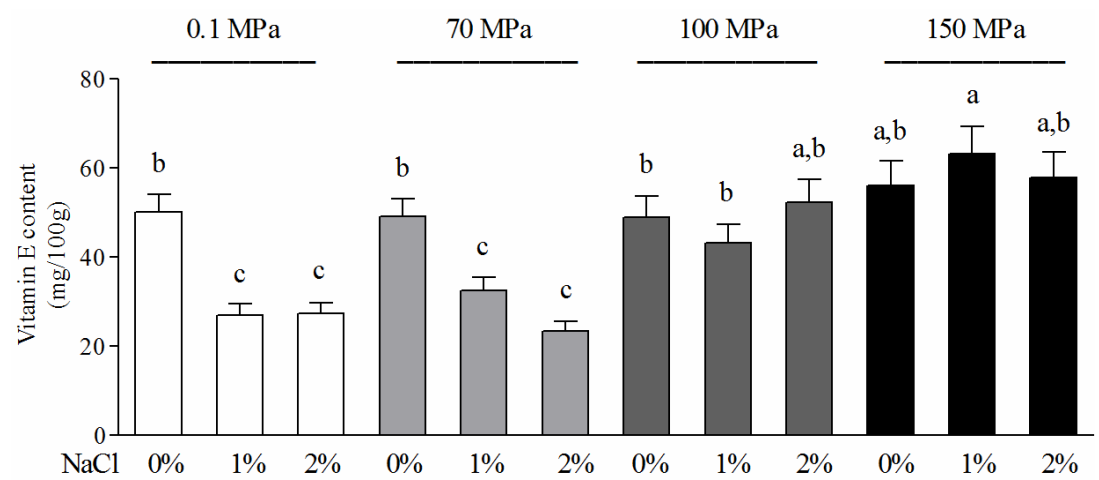

Figure 4. Vitamin E content in egg-yogurt cream with different $\mathrm{NaCl}$ concentration after different $\mathrm{HPH}$ treatments. Data are means +/- SD. Statistical analysis was by the one way ANOVA $(p<0.001)$, using Tukey's as post test. Different letters indicate statistical significance (at least $\mathbf{p}<\mathbf{0 . 0 5}$ ).

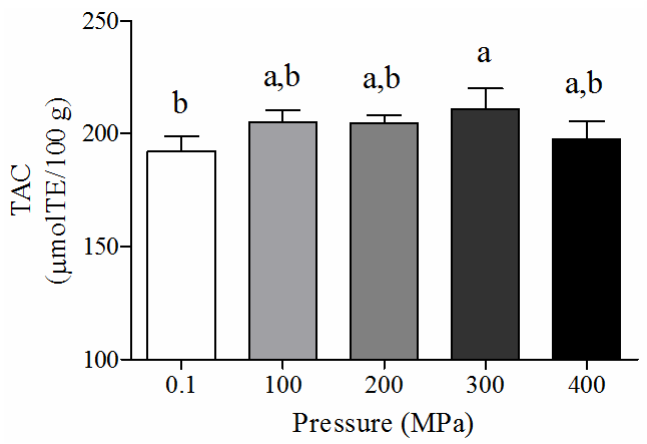

(a)

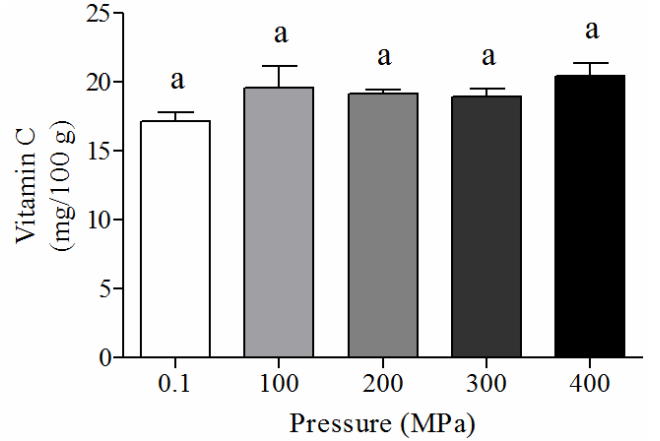

(b)

Figure 5. Total antioxidant capacity (a) and vitamin $C$ content (b) in the mixed vegetable cream after HPH treatments. Data are means +/- SD. Statistical analysis was by the one way ANOVA (TAC $p<0.05$; vitamin C content n.s.), using Tukey's as post test. Different letters indicate statistical significance.

MPa treatment (Figure 6(b)).

\section{Discussion}

New processing technologies are necessary to deliver at the point of food consumption near-absolute chemical and microbial safety and to retain the sensory and nutri- tional quality of fresh ingredients. Particularly, important disadvantages of conventional thermal processing technologies are chemical reactions leading to off flavours, destruction of nutrients, and other losses of product quality. Among novel processing alternatives, high-pressure treatment has been adopted at the fastest rate, so a better 


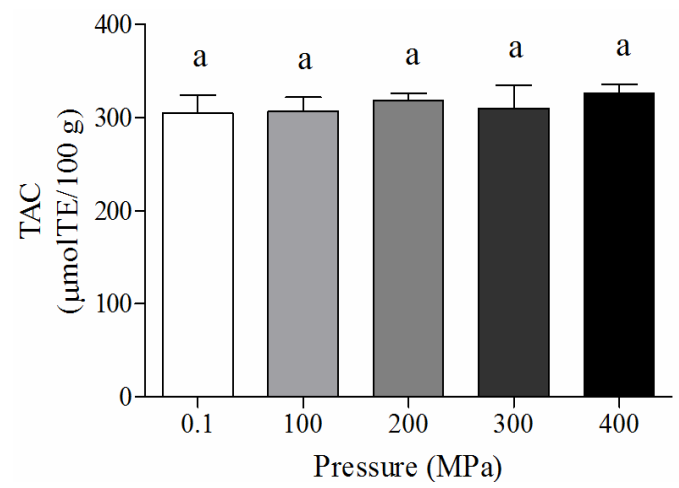

(a)

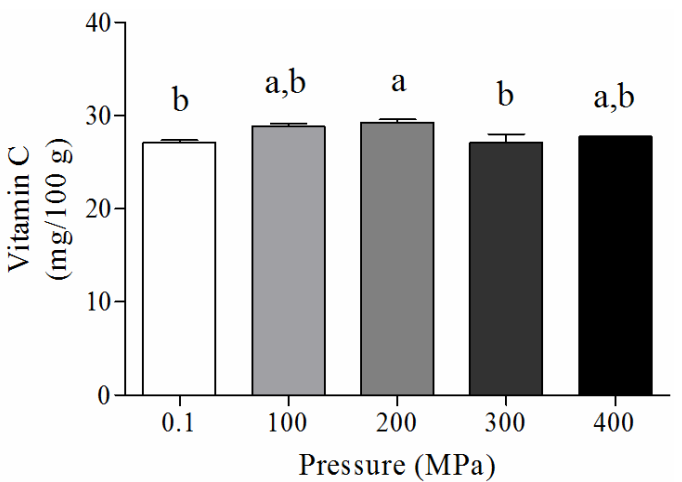

(b)

Figure 6. Total antioxidant capacity (a) and vitamin $\mathrm{C}$ content (b) in the mixed fruit cream after HPH treatments. Data are means +/- SD. Statistical analysis was by the one way ANOVA (TAC n.s.; vitamin C content $p<0.05$ ) using Tukey's as post tes. Different letters indicate statistical significance.

understanding of the impact of this technology on the nutritional value of food from both animal and plant origin is crucial.

Despite the presence of some studies evaluating the effect of HPH processing on foods of animal origin such as meat, milk and dairy products [16], little is known about eggs and egg creams.

In this study, an EYC was prepared using $60 \%(\mathrm{w} / \mathrm{w})$ sunflower oil; EYC lipids, reflecting the fatty acid composition of the ingredients, had a high content of linoleic acid that could be easily peroxidized. HPH processing is reported to increase lipid peroxidation almost proportionally to the content of polyunsaturated fatty acids in the sample [17]; notwithstanding, we did not observe any increase in lipid oxidation in the EYC after HPH processing. It is conceivable that lipid oxidation has been avoided through the inactivation of lipoxygenase; according to the literature lipoxygenase, which catalyses the oxygenation of fatty acids into the corresponding lipid hydroperoxides, may be inactivated by high pressure in different food products [18-20]. In addition, antioxidants in the food matrix could have had a role in the prevention of peroxidation. In our study vitamin $\mathrm{E}$ was not reduced by HPH, in agreement with the findings of Hayashi et al. in eggs [21], and the preservation of tocopherol content could have contributed to the stability of food lipids.

HPH did not influence either the fatty acid composition or the free acidity of EYC, in agreement with Pereda et al. [22] and Rodriguez et al. [23]. The decreased free acidity observed in EYC containing the highest $\mathrm{NaCl}$ concentration could be accounted to changes in lipase activity, already reported in flours having $1 \% \mathrm{NaCl}$ concentration [24].

Regarding vegetable and fruit, a correlation between food microstructure and in vitro bioaccessibility of antioxidant components as carotenes as been already re- ported [25].

Accordingly, the TAC increase observed in the MVC could be explained by the breakdown of intact vegetable cell walls after HPH, with consequent release of intracellular antioxidants, particularly polyphenols and vitamins. Similar results have been reported also by Patras et al. [26] and Suarez-Jacob et al. [27], who observed an increased anti-radical activity in strawberry and blackberry purées, and in apple juices after high pressure processing. On the contrary, no modifications in TAC were observed by Fernandez Garcia et al. [28] in an orange-lemon-carrot juice after high pressure processing, and in MFC in the present study.

This discrepancy could be accounted to the food matrix, and to the molecular relationships between nutrient and non-nutrient components of foods. In fact, there is ample evidence that the different physical state of the type of matrices plays a key role in the release, mass transfer, accessibility, and biochemical stability of many food components [29].

A food matrix influence could also explain data on vitamin C content, which was not modified in the MVC as reported by other Authors in different vegetable products $[27,30,31]$, while was increased in the MFC.

In conclusion, the current work evidences that HPH does not cause lipolysis, lipid peroxidation and vitamin $\mathrm{E}$ loss, at least on the considered food matrix and in the condition studied. Peroxidation is the major cause of quality deterioration of many food products, impairing both flavor and nutritional value, and an increase in peroxidized lipids may pose health risks since they are implicated in the development of different diseases. Thus, the lack of any effect of HPH on the lipid fraction of foods is particularly important.

In plant food, HPH did not affect the nutriational quality but improved it, suggesting the use of this treatment as valid alternative to thermal pasteurization for obtain- 
ing high quality products with preserved nutritional characteristics. The ameliorating effect of HPH on antioxidant and vitamin availability was dependent on the food matrix; a better understanding of the correlation between the processing, the food matrix microstructure, and nutrient bioaccessibility will be fundamental in the production of food products with an increased nutritional value. Although further investigations are needed to better understand the effect of $\mathrm{HPH}$, especially at extreme pressure and temperature combinations, our results open new perspectives for the production of ambient stable products, and contribute to process optimization and food regulation of pressure-sterilized food products.

\section{Acknowledgements}

This study was supported by the European Project "Innovative non Thermal Processing Technologies to Improve the Quality and Safety of Ready-to-Eat Meals (HighQ RTE)" (Project No. 023140) by the EU's 6th Framework Programmés "Food Quality and Safety" activity.

\section{REFERENCES}

[1] J. Kanner, "Dietary Advanced Lipid Oxidation Endproducts Are Risk Factors to Human Health," Molecular Nutrition and Food Research, Vol. 51, No. 9, 2007, pp. 1094-1101. http://dx.doi.org/10.1002/mnfr.200600303

[2] A. M. Jiménez-Monreal, L. García-Diz, M. Martínez-Tomé, M. Mariscal and M. A. Murcia, "Influence of Cooking Methods on Antioxidant Activity of Vegetables," Journal of Food Science, Vol. 74, No. 3, 2009, pp. H97-H103. http://dx.doi.org/10.1111/j.1750-3841.2009.01091.x

[3] M. A. Murcia, A. M. Jiménez-Monreal, L. García-Diz, M. Carmona, L. Maggi and M. Martínez-Tomé, "Antioxidant Activity of Minimally Processed (in Modified Atmospheres), Dehydrated and Ready-to-Eat Vegetables," Food and Chemical Toxicology, Vol. 47, No. 8, 2009, pp. 21032110. http://dx.doi.org/10.1016/j.fct.2009.05.039

[4] M. C. Nicoli, M. Anese and M. Parpinel. "Influence of Processing on the Antioxidant Properties of Fruit and Vegetables," Trends in Food Science \& Technology, Vol. 10, No. 3, 1999, pp. 94-100. http://dx.doi.org/10.1016/S0924-2244(99)00023-0

[5] A. M. Matser, B. Krebbers, R. W. van den Berg and P. V. Bartels. "Advantages of High Pressure Sterilisation on Quality of Food Products," Trends in Food Science \& Technology, Vol. 15, No. 2, 2004, pp. 79-85. http://dx.doi.org/10.1016/j.tifs.2003.08.005

[6] F. Patrignani, L. Vannini, S. L. Sado Kamdem, I. Hernando, R. Marco-Molés, M. E. Guerzoni and R. Lanciotti, "High Pressure Homogenization vs. Heat Treatment: Safety and Functional Properties of Liquid Whole Egg," Food Microbiology, Vol. 36, No. 1, 2013, pp. 63-69. http://dx.doi.org/10.1016/j.fm.2013.04.004
[7] L. Vannini, R. Lanciotti, D. Baldi and M. E. Guerzoni, "Interactions between High Pressure Homogenization and Antimicrobial Activity of Lysozyme and Lactoperoxidase," International Journal of Food Microbiology, Vol. 94, No. 2, 2004, pp. 123-135. http://dx.doi.org/10.1016/j.ijfoodmicro.2004.01.005

[8] L. Iucci, F. Patrignani, M. Vallicelli, M. E. Guerzoni and R. Lanciotti, "Effects of High Pressure Homogenization on the Activity of Lysozyme and Lactoferrin against Listeria monocytogenes," Food Control, Vol. 18, No. 5, 2007, pp. 558-565.

http://dx.doi.org/10.1016/j.foodcont.2006.01.005

[9] M. Di Nunzio, F. Danesi and A. Bordoni, "N-3 PUFA as Regulators of Cardiac Gene Transcription: A New Link between PPAR Activation and Fatty Acid Composition," Lipids, Vol. 44, No. 12, 2009, pp. 1073-1079. http://dx.doi.org/10.1007/s11745-009-3362-y

[10] M. Di Nunzio, D. van Deursen, A. J. Verhoeven and A. Bordoni, "N-3 and N-6 Polyunsaturated Fatty Acids Suppress Sterol Regulatory Element Binding Protein Activity and Increase Flow of Non-Esterified Cholesterol in HepG2 Cells," The British Journal of Nutrition, Vol. 103, No. 2, 2010, pp. 161-167. http://dx.doi.org/10.1017/S000711450999167X

[11] V. Righi, M. Di Nunzio, F. Danesi, L. Schenetti, A. Mucci, E. Boschetti, P. Biagi, S. Bonora, V. Tugnoli and A. Bordoni, "EPA or DHA Supplementation Increases Triacylglycerol, but Not Phospholipid, Levels in Isolated Rat Cardiomyocytes," Lipids, Vol. 46, No. 7, 2011, pp. 627-636. http://dx.doi.org/10.1007/s11745-011-3562-0

[12] P. Dais, A. Spyros, S. Christophoridou, E. Hatzakis, G. Fragaki, A. Agiomyrgianaki, E. Salivaras, G. Siragakis, D. Daskalaki, M. Tasioula-Margari and M. Brenes, "Comparison of Analytical Methodologies Based on 1H and 31P NMR Spectroscopy with Conventional Methods of Analysis for the Determination of Some Olive Oil Constituents," Journal of Agricultural and Food Chemistry, Vol. 55, No. 2, 2007, pp. 577-584. http://dx.doi.org/10.1021/jf061601y

[13] P. Y. Chouinard, L. Corneau, A. Saebø and D. E. Bauman, "Milk Yield and Composition during Abomasal Infusion of Conjugated Linoleic Acids in Dairy Cows," Journal of Dairy Science, Vol. 82, No. 12, 1999, 2737-2745. http://dx.doi.org/10.3168/jds.S0022-0302(99)75530-X

[14] M. Di Nunzio, V. Valli and A. Bordoni, "Pro- and AntiOxidant Effects of Polyunsaturated Fatty Acid Supplementation in HepG2 Cells," Prostaglandins, Leukotrienes, and Essential Fatty Acids, Vol. 85, No. 3-4, 2011, pp. 121-127. http://dx.doi.org/10.1016/j.plefa.2011.07.005

[15] P. Ciancaglini, H. L. Santos, K. R. P. Daghastanli and G. Thedei Jr., "Using a Classical Method of Vitamin C Quantification as a Tool for Discussion of Its Role in the Body," Biochemistry and Molecular Biology Education, Vol. 29, No. 3, 2001, pp. 110-114.

[16] N. K. Rastogi, K. S. M. S. Raghavarao, V. M. Balasubramaniam, K. Niranjan and D. Knorr, "Opportunities and Challenges in High Pressure Processing of Foods," Critical Reviews in Food Science and Nutrition, Vol. 47, No. 1, 2007, pp. 69-112. 
http://dx.doi.org/10.1080/10408390600626420

[17] F. Guéraud, M. Atalay, N. Bresgen, A. Cipak, P. M. Eckl, L. Huc, I. Jouanin, W. Siems and K. Uchida, "Chemistry and Biochemistry of Lipid Peroxidation Products," Free Radical Research, Vol. 44, No. 10, pp. 1098-112. http://dx.doi.org/10.3109/10715762.2010.498477

[18] M. E. Hendrickx, L. Ludikhuyze, I. Van den Broeck and C. Weemaes, "Effects of High Pressure on Enzymes Related to Food Quality," Trends in Food Science \& Technology, Vol. 9, No. 5, 1998, pp. 197-203. http://dx.doi.org/10.1016/S0924-2244(98)00039-9

[19] C. M. Shook, T. H. Shellhammer and S. J. Schwartz, "Polygalacturonase, Pectinesterase, and Lipoxygenase Activities in High-Pressure-Processed Diced Tomatoes," Journal of Agricultural and Food Chemistry, Vol. 49, No. 2, 2001, pp. 664-668. http://dx.doi.org/10.1021/jf000558q

[20] I. Indrawati, L. R. Ludikhuyze, A. M. Van Loey and M. E. Hendrickx, "Lipoxygenase Inactivation in Green Beans (Phaseolus vulgaris L.) Due to High Pressure Treatment at Subzero and Elevated Temperatures," Journal of Agricultural and Food Chemistry, Vol. 48, No. 5, 2000, pp. 1850-1859. http://dx.doi.org/10.1021/jf990937n

[21] R. Hayashi, Y. Kawamura, T. Nakasa and O. Okinaka, "Application of High Pressure to Food Processing: Pressurization of Egg White and Yolk, and Properties of Gels Formed," Agricultural Biology and Chemistry, Vol. 53, No. 11, 1989, pp. 2935-2939. http://dx.doi.org/10.1271/bbb1961.53.2935

[22] J. Pereda, V. Ferragut, J. M. Quevedo, B. Guamis and A. J. Trujillo, "Effects of Ultra-High-Pressure Homogenization Treatment on the Lipolysis and Lipid Oxidation of Milk during Refrigerated Storage," Journal of Agricultural and Food Chemistry, Vol. 56, No. 16, 2008, pp. 7125-7130. http://dx.doi.org/10.1021/jf800972m

[23] L. M. Rodríguez-Alcalá, F. Harte and J. Fontecha, "Fatty Acid Profile and CLA Isomers Content of Cow, Ewe and Goat Milks Processed by High Pressure Homogenization” Innovative Food Science and Emerging Technologies, Vol. 10, No. 1, 2009, pp. 32-36.

http://dx.doi.org/10.1016/j.ifset.2008.10.003

[24] A. F. Doblado-Maldonado, E. A. Arndt and D. J. Rose, "Effect of Salt Solutions Applied During Wheat Conditioning on Lipase Activity and Lipid Stability of Whole Wheat Flour," Food Chemistry, Vol. 140, No. 1-2, 2013, pp. 204-209. http://dx.doi.org/10.1016/j.foodchem.2013.02.071

[25] C. A. Svelander, P. Lopez-Sanchez, P. D. A. Pudney, S. Schumm and M. A. G. Alminger, "High Pressure Homogenization Increases the in Vitro Bioaccessibility of $\alpha$ and $\beta$-Carotene in Carrot Emulsions but Not of Lycopene in Tomato Emulsions" Journal of Food Science, Vol. 76, No. 9, 2011, pp. H215-H225. http://dx.doi.org/10.1111/j.1750-3841.2011.02418.x

[26] A. Patras, N. P. Brunton, S. Da Pieve and F. Butler, "Impact of High Pressure Processing on Total Antioxidant Activity, Phenolic, Ascorbic Acid, Anthocyanin Content and Colour of Strawberry and Blackberry Purées," Innovative Food Science \& Emerging Technologies, Vol. 10, No. 3, 2009, pp. 308-313. http://dx.doi.org/10.1016/j.ifset.2008.12.004

[27] Á. Suárez-Jacobo, C. E. Rüfer, R. Gervilla, B. Guamis, A. X. Roig-Sagués and J. Saldo, "Influence of Ultra-High Pressure Homogenisation on Antioxidant Capacity, Polyphenol and Vitamin Content of Clear Apple Juice," Food Chemistry, Vol. 127, No. 2, 2011, pp. 447-454. http://dx.doi.org/10.1016/j.foodchem.2010.12.152

[28] A. Fernández García, P. Butz, A. Bognàr and B. Tauscher, "Antioxidative Capacity, Nutrient Content and Sensory Quality of Orange Juice and an Orange-Lemon-Carrot Juice Product After High Pressure Treatment and Storage in Different Packaging," European Food Research and Technology, Vol. 213, No. 4-5, 2001, pp. 290-296. http://dx.doi.org/10.1007/s002170100332

[29] J. Parada and J. M. Aguilera, "Food Microstructure Affects the Bioavailability of Several Nutrients," Journal of Food Science, Vol. 72, No. 2, 2007, pp. R21-R32. http://dx.doi.org/10.1111/j.1750-3841.2007.00274.x

[30] P. Butz, A. Fernández García, R. Lindauer, S. Dieterich, A. Bognár and B. Tauscher, "Influence of Ultra High Pressure Processing on Fruit and Vegetable Products," Journal of Food Engineering, Vol. 56, No. 2-3, 2003, pp. 233-236. http://dx.doi.org/10.1016/S0260-8774(02)00258-3

[31] B. Krebbers, A. M. Matser, S. W. Hoogerwerf, R. Moezelaar, M. M. M. Tomassen and R. W. van den Berg, "Combined High-Pressure and Thermal Treatments for Processing of Tomato Puree: Evaluation of Microbial Inactivation and Quality Parameters," Innovative Food Science \& Emerging Technologies, Vol. 4, No. 4, 2003, pp. 377 385. http://dx.doi.org/10.1016/S1466-8564(03)00045-6. 